\title{
O CORPO DAS CRIANÇAS NAS AULAS DE ATLETISMO NA ESCOLA
}

\author{
Carlos Fabre Miranda*
}

\begin{abstract}
RESUMO: Problematizar a ideia instrumental do ensino do corpo, apresentando alternativas e exemplos embasados no atletismo, é o principal objetivo que este texto busca aprofundar. Procura-se entender primeiramente o porquê de se trabalhar o corpo na educação física escolar e, assim, apresentar como se desenvolveram algumas das críticas à visão instrumental com que seguidamente é tratada esta disciplina. Algumas considerações sobre o atletismo na escola também são apresentadas. Além da simples correção de gestos, serão mostradas alternativas para se abordar, mais do que os procedimentos, os conceitos e as atitudes nos esportes e, em especial, no atletismo.
\end{abstract}

Palavras-chave: Corpo. Educação física escolar. Atletismo.

THE BODY OF CHILDREN IN ATHLETICS CLASSES AT SCHOOL

ABSTRACT: To question the idea of instrumental body teaching, presenting alternatives and examples based on athletics, are the main objectives that this paper seeks to deepen. This text aims to understand first why the body is worked in physical education and afterwards to show how some of the critiques on that instrumental view with which this subject is often treated. Some considerations about athletics at school are also presented. Beyond simple correction of gestures, there will be shown alternatives to address, rather than procedures, concepts and attitudes in sports and athletics specially.

Key words: Body. Physical education. Athletics.

Mestre em Ciências do Movimento Humano e professor da Prefeitura Municipal de Porto Alegre. E-mail: carlosfabremiranda@terra.com.br 
O corpo das crianças nas aulas de atletismo na escola

\section{Introdução}

$\mathscr{P}$

roblematizar o corpo, sua construção e suas relações com o esporte nas aulas de educação física realizadas nas escolas já se apresentam como temas relevantes e desafiadores, se tomados individualmente. Analisados em conjunto, ganham importância para o debate acadêmico, e nos seus cruzamentos, em muitos momentos, merecem um aprofundamento. Nesse sentido, este texto pretende tecer relações entre as aulas de educação física realizadas nas escolas, compreendendo o mérito de abordar o corpo nestas aulas e apresentando propostas. Por exemplo, mostrar que esportes como o atletismo podem ser abordados em uma perspectiva que não se restrinja ao ensino e a aprimoramentos de movimentos técnicos, buscando abordar elementos além de apenas ensinar a saber fazer, que predomina nas aulas da referida disciplina escolar, aprofundado procedimentos, conceitos e atitudes.

Assim, este artigo pretende abordar um tema que perpassa as aulas de educação física escolar. Além de entender por que é importante abordar o corpo neste contexto, busca-se compreender esta relação especificamente com a educação física. Vejo como importante o entendimento, ainda, de que o simples ensino do jeito de fazer não esgota as possibilidades do ensino dos esportes, com especial atenção para o atletismo.

\section{Por que compreender o corpo nas aulas de educação física}

Sendo o atletismo um dos conteúdos possíveis de ser abordados nas aulas de educação física escolar, assim como a sua prática está relacionada diretamente com o corpo dos alunos, pretendo apresentar algumas questões que salientem esta relação direta. É o corpo que se desloca em corridas e saltos e é ele que impulsiona os implementos nos lançamentos. É ele, ainda, que realiza atividades adaptadas, com a intenção de inscrever em si mesmo os significados do atletismo ou de outros esportes. $\mathrm{O}$ atletismo muitas vezes constitui-se como uma identidade do privilégio dos mais aptos, no qual os alunos produzem gestos que constroem o corpo socialmente, no contexto da educação física e dos esportes.

O corpo - evidenciado, em suas possibilidades e limites, nas aulas da educação física escolar - ainda se apresenta como um dos temas 
presentes e tencionados nas discussões acadêmicas, como mostra Louro $(2000$, p. 60):

(...) as teorias educacionais e as inúmeras disciplinas que constituem os cursos de formação docente pouco ou nada nos dizem sobre os corpos - dos estudantes ou dos nossos. Com exceção da Educação Física, que faz do corpo e de seu adestramento o foco central de seu agir, todas as demais áreas e disciplinas parecem ter conseguido produzir seu "corpo de conhecimento" sem corpo. No "sagrado" campo da educação não apenas separamos mente o corpo, mas, mais do que isso, suspeitamos do corpo. Aparentemente estamos, nas escolas e universidades, lidando exclusivamente com ideias e conceitos que, de algum modo, fluem de seres incorpóreos.

O corpo se apresenta, assim, como algo que, além de separado da mente e "suspeito", como indica a autora, é tido na educação física, muitas vezes, como algo a ser adestrado, disciplinado, docilizado. Esta disciplina busca enquadrar um corpo hostil e selvagem em algo civilizado e compatível com normas sociais aceitáveis. Se os professores buscam "ter em mente" que os alunos devem compreender melhor seus corpos, de acordo com Darido e Rangel (2005), este tema deve estar presente nas aulas de educação física; ao abordar o que se espera que os alunos saibam, é importante que tenham compreensão do próprio corpo:

Conhecer o próprio corpo pode ser o princípio de todo o conhecimento que alguém pode ter, pois entendemos que conhecer o corpo é conhecerse a si mesmo. Esperamos que os alunos na educação básica aprendam a conhecer o próprio corpo, seus detalhes internos, sua subjetividade e afetividade interpessoal. Eles também não devem se limitar nesse conhecimento, pois seu corpo está relacionado ao seu ser, aos outros e à cultura, enfim, ao mundo que nos cerca e ao contexto mais amplo do ambiente. (Darido \& Rangel, op. cit., p. 140)

Com este argumento, concordo que o conhecimento do corpo é importante e as aulas de educação física são um espaço privilegiado para este aprendizado. No entanto, alguns autores colocam esta afirmação em xeque. Um exemplo claro pode ser notado no título do livro de João Paulo Medina, apresentando que $A$ educação física cuida do corpo... e "mente". Nesta frase, ao tratar da mente, o autor não trata somente da mente das pessoas, das suas ideias e construtos, mas faz referência ao verbo mentir. 
O corpo das crianças nas aulas de atletismo na escola

Medina, que ainda no início da década de 1990 afirmava que a educação física precisava entrar em crise, realiza boa parte das suas críticas buscando questionar a imagem do corpo como instrumento para algo: "A Educação Física não sairá de sua superficialidade enquanto não se posicionar criticamente em relação aos seus valores, ou, em outras palavras, não se questionar quanto ao real valor de sua prática para as pessoas e para a comunidade a que serve" (Medina, 2006, p. 73).

Outra perspectiva é a apresentada por um grupo de professores de Educação Física denominado Coletivo de Autores (Soares et al., 1992), para quem o corpo é apresentado como uma linguagem que, através da expressão corporal, se constitui como um conhecimento universal, patrimônio da humanidade que igualmente precisa ser transmitido e assimilado pelos alunos na escola. A sua ausência também impede que o homem e a realidade sejam entendidos dentro de uma visão de totalidade. Estes autores questionam como compreender a realidade natural e social, complexa e contraditória, sem uma reflexão sobre a cultura corporal humana.

Ao tratar da educação física escolar, este coletivo de pesquisadores forjou um termo recorrente, a expressão cultura corporal, que se apresenta assim:

A Educação Física é uma disciplina que trata, pedagogicamente, na escola, do conhecimento de uma área denominada aqui de cultura corporal. Ela será configurada com temas ou formas de atividades, particularmente corporais, como: jogo, esporte, dança ou outras, que constituirão seu conteúdo. O estudo desse conhecimento visa a apreender a expressão corporal como linguagem. (Soares et al., op. cit., p. 61-62)

A importância do Coletivo de Autores para o debate acadêmico na educação física brasileira é inquestionável, mesmo que o discurso de transformação social e a ação revolucionária por esta disciplina estejam presentes em muitos momentos. A abordagem crítico-superadora, apresentada por estes pesquisadores, auxilia no entendimento de que o corpo é a "inscrição que se move, e cada gesto aprendido e internalizado revela trechos da história da sociedade a que pertence" (Soares, 2006, p. 109). Essa citação reforça a concepção de que o corpo é uma construção e deve ser entendido a partir do contexto social em que está inserido culturalmente. 
As considerações apresentadas mostram por que é importante que os alunos conheçam o próprio corpo. Da mesma forma, é preciso que os professores reconheçam que o corpo pode ser uma linguagem, através da expressão corporal, e que é uma construção cultural com influências diretas da sociedade. No próximo momento, pretendo apresentar o atletismo como um dos conteúdos que contribuem para isso e que pode ser abordado de maneira a não se deter somente na correção de gestos e na aplicação instrumental da técnica mais adequada.

\section{Atletismo nas escolas}

Muitas vezes, o atletismo é visto pelos alunos como um esporte pouco atrativo e "sem graça". Tal fato, por vezes, desmotiva professores que não veem no ensino do atletismo um desafio e também não vislumbram um conteúdo capaz de ser ensinado num contexto escolar, onde há dificuldades para incluir este conteúdo em seus planos de aula. Apresentarei, agora, autores que abordam estas adversidades ao se inserir o atletismo no contexto escolar.

Matthiesen (2007), ao tratar das dimensões educacionais do atletismo, apresenta inicialmente que existem diferenças entre o objetivo de sua prática na escola e nos clubes. A escola - de ensino fundamental, médio e superior - tem como objetivo principal a transmissão do conhecimento construído historicamente. Por outro lado, os clubes buscariam a participação em competiçōes. Os limites entre essas duas diferentes dimensões, indicadas pela autora, algumas vezes são sobrepostos, visto que competições entre escolas são cada vez mais comuns. E os clubes, pela pouca quantidade de atletas, às vezes inscrevem-nos em provas que não foram treinadas/praticadas. Deixando de lado este tema polêmico de ensinar e/ou desenvolver o esporte, volto minha atenção para o contexto escolar.

A afirmação "atletismo se aprende na escola" (Matthiesen, op. cit.) é, no mínimo provocante, quando olhamos a realidade atual da educação física nas escolas brasileiras. Os exemplos trazidos pela autora podem ser facilmente transferidos do contexto da cidade de Rio Claro, no interior de São Paulo, para cidades do Rio Grande do Sul e de outras partes do país. Os relatos apresentam a pequena vivência que alunos de ensino superior tiveram com o atletismo em suas vidas escolares. Esse 
O corpo das crianças nas aulas de atletismo na escola

fato resulta em um interesse reduzido por parte dos futuros professores. Mesmo sendo um esporte com modalidades, origens, regras e técnicas diversas, o atletismo é trabalhado, na maioria dos casos, em um ou dois semestres da graduação.

Outro autor, Bragada (2000), indica que grande parte das escolas, em especial da rede pública, não possui sequer espaço para a prática de esportes como o atletismo. As modalidades coletivas possuem um espaço - físico e simbólico - privilegiado, no ensino da educação física no Brasil, em especial as modalidades com bola. O futebol, especificamente, é um conteúdo dominante no imaginário dos alunos e no cotidiano das aulas de educação física.

Um pesquisador de referência neste assunto é Kunz (1998), que aponta como o atletismo é "deixado de lado", pois ensiná-lo se apresenta como um processo dramático. Ele salienta:

A preferência por atividades jogadas não está somente na falta de ludicidade, como se apresentam as chamadas "provas" de atletismo, mas, na maioria dos casos, por lembranças de insucesso ou de uma vivência não bem sucedida pelos parâmetros normais como essas provas se apresentam. (Kunz, op. cit., p. 23)

Acredito que, de certa forma, a suposta grande demanda física necessária para se correr, saltar e lançar com eficiência contribui para este entendimento. Em muitos casos, o atletismo é abordado com enfoque voltado em grande medida para o desenvolvimento das valências físicas e abordagens voltadas somente para o treinamento de força, velocidade e resistência, que serão demandadas nas provas em si e na busca de um aperfeiçoamento dos movimentos específicos de cada prova. É inegável a importância do desenvolvimento da força, resistência e velocidade; a questão é compreender que, para as crianças, o elemento lúdico deve ser preponderante para que modalidades como o atletismo sejam atrativas. Ao se abordar o atletismo com séries, repetiçôes, volume, intensidade etc., estamos buscando em uma linguagem do treinamento desportivo elementos para uma modalidade que, no seu dia a dia, trata do treinamento em si, mas se apresenta como pouco atrativa para crianças e jovens, salientando a visão instrumental do corpo, como discutido anteriormente.

No próximo tópico serão apresentados elementos de trabalhos já realizados que abordam o atletismo, na intenção de superar a ideia de 
somente enfocar questões procedimentais nas aulas de educação física, ou seja, ultrapassando o saber fazer.

\section{Para além dos procedimentos técnicos no atletismo}

Autores como Prado e Matthiesen (2007) salientam que o ensino de uma modalidade esportiva em aulas de educação física é algo bastante frequente no campo escolar. No entanto, estes autores salientam questões que já foram abordadas anteriormente. Segundo eles, durante as aulas, "muitos professores têm como objetivo único ensinar o movimento técnico, preocupando-se apenas com o 'saber fazer', quando não com o 'saber fazer' bem" (Prado \& Matthiesen, op. cit., p. 120). Os pesquisadores salientam que isso, infelizmente, faz com que outras possibilidades de desenvolvimento do conteúdo sejam deixadas em segundo plano, como é o caso dos conceitos e atitudes a ele inerentes.

Darido e Rangel (2005) afirmam que a principal atenção é dada ao fazer nas aulas de educação física na escola, fato este que pode ser analisado quando refletimos sobre o histórico de suas práticas pedagógicas. Ao serem analisadas as concepções da educação física no Brasil, os procedimentos (o fazer) possuem uma maior presença nas aulas em relação aos conceitos (o por que fazer) e às atitudes (para que fazer), restringindo, com isso, a capacidade educacional global dessa disciplina (idem, ibid.).

Prado e Matthiesen (op. cit., p. 121) acrescentam: "Isso acaba, sem dúvida, contribuindo para a ideia errônea de que a Educação Física é uma disciplina secundária no processo de formação da criança, e que o conteúdo ensinado dentro de suas aulas pode muito bem ser substituído pelos intervalos e recreios escolares". Os autores buscam refletir sobre suas possibilidades de ensino em aulas de educação física, realçando a importância do resgate dos movimentos técnicos da prova para a compreensão de seu desenvolvimento ao longo de sua história; uma alternativa importante para o ensino do atletismo.

Além disso, e partindo do pressuposto de que não devemos entender o movimento humano como algo restrito ao caráter biológico de sua prática, mas concebê-lo como um fator da cultura, relatamos uma experiência que foi efetuada no Colégio de Aplicação da Universidade Federal do Rio Grande do Sul (UFRGS), em 2007, e relatada em trabalho acadêmico divulgado em evento científico que buscou apresentar para os 
O corpo das crianças nas aulas de atletismo na escola

alunos vivências em diversas modalidades. Além disso, foram elencados outros aspectos importantes e educativos presentes em grandes eventos esportivos, como os Jogos Pan-Americanos no Rio de Janeiro (Miranda, 2008), abordados naquela oportunidade.

\section{Considerações finais}

Após tratar de temas tão importantes e que ainda trazem elementos para um debate - como o entendimento do corpo e a necessidade de que os alunos aprendam sobre o corpo nas aulas de educação física -, serão trazidas considerações que cruzam este temas com outros apresentados ao longo deste texto.

Autores críticos como Medina (2007) e o Coletivo de Autores (1992) foram importantes para consolidar e embasar a educação física escolar como uma área relevante. Mesmo que o corpo seja visto em muitos momentos como um instrumento, devendo servir para algo, este entendimento ainda se encontra presente em relação à disciplina. Buscamos, assim, apresentar que é importante e possível superar este entendimento. O corpo é onde se inscrevem a cultura e a sociedade nos indivíduos e ele também constitui uma linguagem através da expressão corporal.

Por fim, esportes como o atletismo - que trata diretamente e, em muitos casos, se confunde com o desenvolvimento das valências físicas são abordados somente levando-se em conta os procedimentos, que seria o saber fazer, e deixando em um plano secundário aspectos importantes como os conceitos e as atitudes abordados por Darido e Rangel (2005). A partir dos exemplos de como podem ser abordados estes aspectos, acredito ser necessário incentivar os professores a buscarem construir a sua prática pedagógica tendo o entendimento das dimensões possíveis, não somente no atletismo, mas nos esportes em geral.

\section{Referências}

BRAGADA, J. O atletismo na escola: proposta programática para abordagem dos lançamentos leves. Horizonte - Revista de Educação Física e Desporto, Lisboa, v. 17, n. 99, p. 1-12, jun./jul. 2000.

DARIDO, S.; RANGEL, I. Educação física na escola: implicações para a prática pedagógica. Rio de Janeiro: Guanabara Koogan, 2005. 
KUNZ, E. Didática da educação física. Ijuí: Unijuí, 1998.

LOURO, G.L. Corpo, escola e identidade. Educação \& Realidade, Porto Alegre, v. 25, n. 2, p. 59-75, jul./dez. 2000.

MATTHIESEN, S. Atletismo: teoria e prática. Rio de Janeiro: Guanabara Koogan, 2007.

MATTHIESEN, S.; PRADO, V.M. Para além dos procedimentos técnicos: o atletismo em aulas de educação física. Motriz, Rio Claro, v. 13, n. 2, p. 120-127, abr./jun. 2007.

MEDINA, J.P. A educação física cuida do corpo... e "mente". Campinas: Papirus, 2007.

MIRANDA, C.F. Panalfas: relato de oficina para séries iniciais dos Jogos Pan-Americanos do Rio 2007. In: CONGRESSO DO DESPORTO E EDUCAÇÃO FÍSICA DOS PAÍSES DE LÍNGUA PORTUGUESA, 12., Anais... Porto Alegre: UFRGS, 2008.

SOARES, C.L.S. et al. Metodologia do ensino de educação física. São Paulo: Cortez, 1992.

SOARES, C.L.S. (Org.). Corpo e história. Campinas: Autores Associados, 2006.

Recebido em 5 de abril de 2011.

Aprovado em 30 de junho de 2012. 